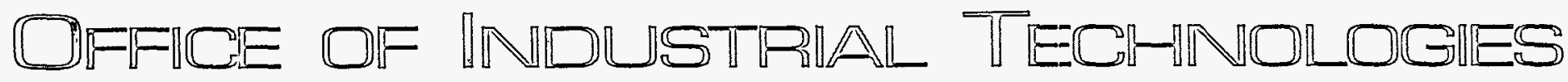

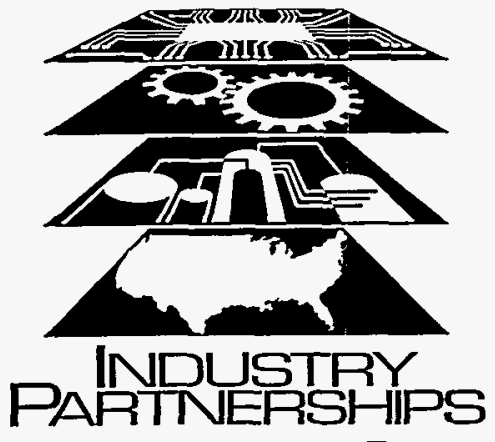

U.S. DEPARTMENT OF ENERGY
Travel forward in time and imagine what United States' industries could be like in the year 2020.

- Industries are competing more effectively in global markets.

- The rate of energy use has decreased due to increases in industrial efficiency.

- More industrial jobs have been created.

- Manufacturing plants have made significant strides toward reducing or eliminating their wastes.

- Greenhouse gas emissions have been reduced to 1990 levels.

- Research and development efforts have brought forth new technologies, resulting in an improved environment.
The future scenario is not wishful thinking. In fact, U.S. industries are making significant progress in turning this vision of the future into reality. And the U.S. Department of Energy's (DOE's) Office of Industrial Technologies (OIT) is helping. OIT is catalyzing and supporting industry progress in a multitude of ways.

OIT is part of DOE's Office of Energy Efficiency and Renewable Energy and works side by side with specific industries, trade associations, research organizations, universities, national laboratories, utilities, and State and Federal agencies to achieve both national and industrial goals. OIT's successful partnerships within both public and private sectors have helped find numerous opportunities for energy savings and pollution prevention.

OIT programs and activities for research, development, and deployment of advanced technologies are designed to increase energy efficiency, prevent pollution, and improve productivity. OIT's research focus is on energy supply technologies, industrial process improvements, and pollution prevention technologies.

Many OIT-funded processes and technologies are now commercialized and being used by industry. Not only are these technologies saving energy and reducing or utilizing wastes, they are also increasing industries' profitability and overall competitiveness.

The impacts of OIT's activities have been extensive and industry-wide. More than 65 OIT-supported research and development $(\mathrm{R} \& D)$ projects have resulted in technologies and process improvements that industries are currently using; other projects have contributed significantly to basic knowledge of industrial processes.

To date, OIT-developed technologies and processes have saved U.S. industry more than $\$ 1.6$ billion from reduced energy use. The net cumulative benefit of these technologies (industrial savings less Federal investment) was approximately $\$ 478$ million for fiscal year 1994.

In addition to researching technologies and forming partnerships, OIT is also pursuing other ways to help our Nation and industries achieve key goals through the adoption of innovative technologies. For instance, OIT is spearheading the Industries of the Future strategy, a joint Government/industry process designed to leverage the scarce resources available for technology research, development, and deployment for maximum results. OIT is also doing its part to reduce the threat of global climate change by directing several new programs under DOE's "Energy Partnerships for a Strong Economy."

\section{Industries of the Future}

OIT's Industries of the Future strategy is an innovative approach to help the materials and process industries address the broader goals of energy efficiency, competitiveness, environmental performance, jobs creation, and technology development. This strategy aligns Government research, development, and demonstration investments in new technologies with industry's needs and interests. Open communications facilitate teaming and interaction among all participants to shorten the cycle times of moving innovative technologies from concept to marketplace. 
Information available through the Motor Challenge program helps industry participants save money, increase productivity, and improve environmental quality by using energy-efficient electric motor systems. (Photo by Jeff Uhrlaub)

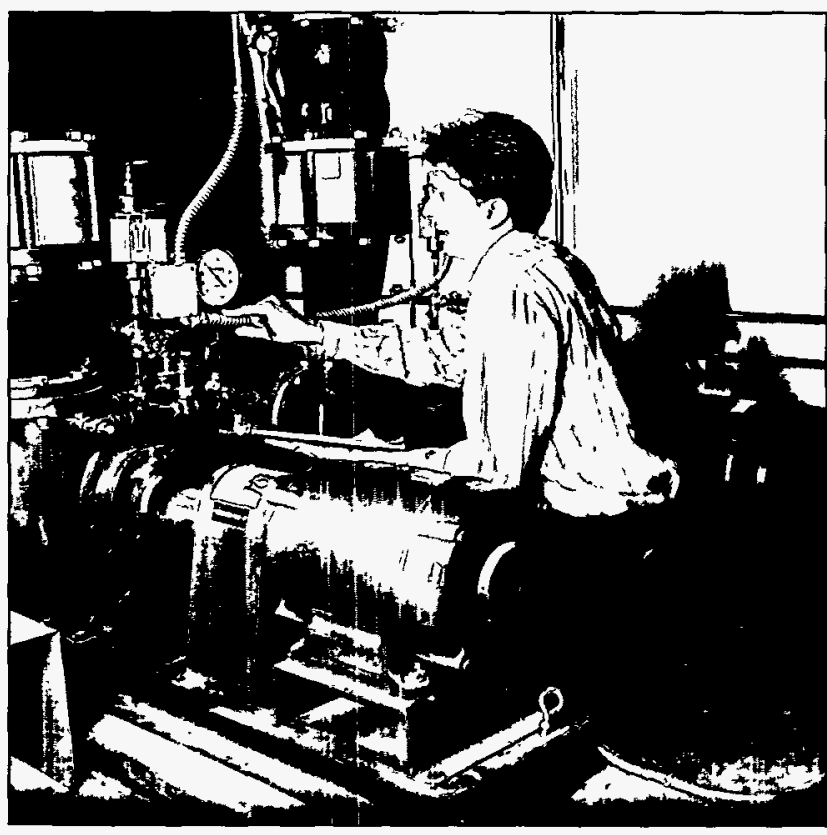

Policy Act of 1992 and other legislation, is playing a central role in meeting the national goals for emissions reduction.

A key program aimed at the industrial sector is Climate Wise, sponsored by DOE and the U.S. Environmental Protection Agency. Climate Wise encourages industrial companies to voluntarily identify and pledge to implement cost-effective actions leading to reductions in harmful greenhouse gases. Companies can create their own reduction activities as well as participate in existing OIT-sponsored programs such as Motor Challenge, $\mathrm{NICE}^{3}$ (National Competitiveness through Energy, Environment, and Economics), and Industrial Assessment Centers (formerly Energy Analysis and Diagnostic Centers).

The Motor Challenge program helps industries to improve their profitability while reducing greenhouse gas emissions through the increased use of energyefficient electric motor systems.

The $\mathrm{NICE}^{3}$ program provides grants to industry/State partnerships to demonstrate energy-efficient, waste-reducing technologies.

Small- and medium-size manufacturers across the nation are implementing recommendations from 


\section{DISCLAIMER}

This report was prepared as an account of work sponsored by an agency of the United States Government. Neither the United States Government nor any agency thereof, nor any of their employees, make any warranty, express or implied, or assumes any legal liability or responsibility for the accuracy, completeness, or usefulness of any information, apparatus, product, or process disclosed, or represents that its use would not infringe privately owned rights. Reference herein to any specific commercial product, process, or service by trade name, trademark, manufacturer, or otherwise does not necessarily constitute or imply its endorsement, recommendation, or favoring by the United States Government or any agency thereof. The views and opinions of authors expressed herein do not necessarily state or reflect those of the United States Government or any agency thereof. 


\section{DISCLAIMER}

Portions of this document may be illegible in electronic image products. Images are produced from the best available original document. 
to reduce pollution. OIT is pursuing a variety of waste-minimizing or waste-reducing technologies including:

- Recovery of energy from liquid waste streams

- Conversion of plastics to feedstock material

- Improved use of waste heat through process thermal integration

- Reduction of solvent use

- Reclamation of foundry sand

- Recycling of municipal solid waste.

\section{Technology Transfer Brings New Technologies to Market}

Legislation enacted during the 1980 s and 1990 s has made technology transfer a key element of both DOE's and OIT's missions. OIT's active technology transfer program links $\mathrm{R} \& \mathrm{D}$ programs and innovative technologies with the community of potential industrial users.
Key elements of the technology transfer program include: communicating to DOE's industrial constituencies; leveraging Federal, State, local, and industry resources; providing direct technical, informational, and educational support to the industrial sector; and designing each project to maximize the potential for commercial success. The program also measures OIT's progress toward accelerating the awareness, acceptance, and adoption of technologies that will improve the total performance of U.S. industry.

\section{Productivity through Technology}

OIT's partnerships with industry are resulting in improved competitiveness for U.S. industries, an increase in energy efficiency, and an improvement in environmental quality. OIT's motto, "Productivity through Technology," is a fitting phrase that applies to all its activities. The energy, economic, and environmental benefits from new industrial technologies translate to a cleaner, more productive world for everyone.

To receive information about OIT-sponsored technologies or participating in Climate Wise, Motor Challenge, NICE ${ }^{3}$, or Industrial Assessment

Centers, contact the Energy Efficiency and Renewable Energy

Clearinghouse: 800-DOE-EREC [8D0-DOE-3732].

This document was produced for the U.S. Department of Energy [DOE] by the National Renewable Energy Laboratory, a DOE national laboratory. DOE/GO-10095-097

DE94006881

April 1995

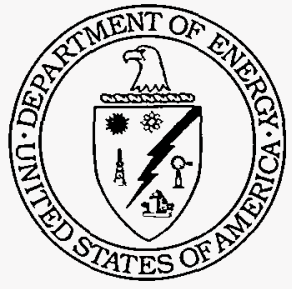

\section{U.S. Department of Energy 1000 Independence Avenue, SW Washington, DC 20585}

